\title{
CHANGE OF THE ACID NUMBER OF WHEAT GRAIN FAT WHILE STORED IN LABORATORY CONDITIONS
}

\author{
Yury D. Gavrichenkov*, Alexander S. Razvorotnev, Ivan A. Kechkin, Irina A. Verezhnikova \\ All-Russian Scientific and Research Institute for Grain and Products of its Processing - \\ Branch of the V.M. Gorbatov Federal Research Center for Food Systems of Russian Academy of Sciences, Moscow, Russia
}

KEY WORDS:

grain storage, storage temperature, relative air humidity, acid number of fat, humidity of grain

\begin{abstract}
To establish the deadline for freshness and shelf life of wheat during long-term storage, the indicator is considered - acid number of fat (ANF) mg KOH per gram of fat in the stored grain sample. To study the nature of the change of this indicator from temperature and relative humidity of the air, the present studies were performed. Samples of grain, harvest 2017, were placed in a desiccator over salt solutions, which were used to set a certain relative air humidity above the surface of the solution in the range from $35 \%$ to $75 \%$. In each desiccator were placed two samples of wheat grain III and IV class weighing about $500 \mathrm{~g}$ each. The grain layer in the desiccators was $70-80 \mathrm{~mm}$. To monitor the state of the samples, the Logger $100 \mathrm{TV}$ temperature and relative humidity recorders were placed inside the grain layer with a recording interval of readings after 2 hours. Periodically sampled grain from each desiccator for the determination of ANF and humidity. Acid number of fat was determined by the accepted standard method.

The uniformity of humidity values in the desiccators $60 \%$ and $75 \%$ occurred after two months of storage. For a relative humidity of $35 \%, 44 \%$ arrived after approximately one month of storage. Some fluctuations in relative humidity values are associated with temperature changes at the storage location (laboratory room), as well as with the opening of a desiccator when taking grain samples to determine humidity and ANF. Fluctuations in relative humidity did not exceed $3 \%$. Significant changes (growth) of ANF were observed in the fourth to fifth month of storage the samples at temperatures above $20^{\circ} \mathrm{C}$, at a storage temperature of $10^{\circ} \mathrm{C}$, practically no significant changes in ANF were observed during 9 months of storage.
\end{abstract}

\section{Introduction}

In conditions of temperature and humidity storage conditions that meet the requirements of regulatory and technical documentation, processes occur in grain and grain products that can lead to a decrease in the organoleptic properties (color, smell, taste) of products, and, consequently, to the loss of its nutritional and commercial value $[1,2,3]$. According to many studies on the storage of grain at moisture below $13.5 \%$ in the grain and grain products, the mold does not develop, changes are mainly due to hydrolytic processes, primarily affecting the lipid fraction of grain products, and are largely determined by the activity of the lipase enzyme that leads to the accumulation of free fatty acids $[4,5,6,7]$. To establish the deadline for freshness and shelf life of wheat during long-term storage, the indicator is the acid number of fat (HP) mg KOH per gram of fat [10]. To study the nature of the change of this indicator from temperature and relative humidity of the air, the present studies were performed. Recent studies $[8,9]$ confirmed that lipase is active even under conditions of low temperatures and humidity; therefore, in grain products stored under conditions of standard humidity, even at low temperatures, there is a slow accumulation of free fatty acids. The accumulation of free fatty acids reflects the indicator «acid number of fat» (ANF), the procedure for determining which is as simple and economical as possible, and which is more informative than other indicators characterizing hydrolytic processes in grain products, leading to a deterioration in their organoleptic properties [3].

\section{Materials and methods}

The studies were carried out at the All-Russian Scientific and Research Institute for Grain and Products of its Processing Branch of the V.M. Gorbatov Federal Research Center for Food Systems of Russian Academy of Sciences

In this connection, it is of interest to consider the effect of grain moisture on the change in the acid value of fat during long-term storage $[10,11,12]$.
Samples of grain, harvest of 2017, were placed in a desiccator over salt solutions, which were used to set a certain relative air humidity above the surface of the solution in the range from 35 to $75 \%$, in accordance with Table $1[13,14]$. Samples were stored from April to November 2018 (inclusive), at three temperatures: $20-27^{\circ} \mathrm{C}$ (average for storage period $-23^{\circ} \mathrm{C}$ ) in the laboratory; $8 \div 10^{\circ} \mathrm{C}$ in the refrigerator and $30^{\circ} \mathrm{C}$ in the thermostat. Five desiccators were placed in the laboratory: E1, E2, E3, E4 and E7, in the thermostat E5 and in the refrigerator E6.

Saturated salt solutions were poured into the bottom of the desiccators to create the desired relative air humidity in the internal volume. Samples of grain were placed above the solutions.

Before being stored in desiccators, the grain was cleaned of impurities on an air-sieve laboratory separator.

Salt solutions for setting the required values of relative humidity according to GOST 29244-91 (ISO 483-88)

\begin{tabular}{|c|c|c|c|c|}
\hline 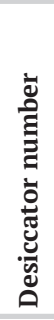 & 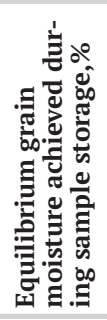 & 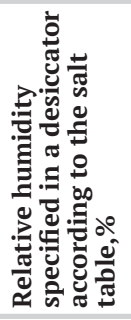 & $\begin{array}{l}\text { Name of saturated salt solution } \\
\text { Average expected storage } \\
\text { temperature }\end{array}$ & 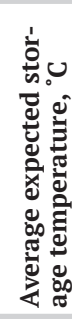 \\
\hline E 1 & 12.4 & 55 & Sodium bichromate $\mathrm{Na}_{2} \mathrm{Cr}_{2} \mathrm{O}_{7} \cdot 2 \mathrm{H}_{2} \mathrm{O}$ & 20 \\
\hline E 2 & 10.5 & 35 & Magnesium chlorine $\mathrm{MgCl}_{2}$ & 20 \\
\hline E 3 & 13.7 & 65 & Ammonium nitrate $\mathrm{NH}_{4}\left(\mathrm{NO}_{3}\right)$ & 20 \\
\hline E 4 & 11.2 & 44 & Potassium carbonate $\mathrm{K}_{2} \mathrm{CO}_{3} \cdot 2 \mathrm{H}_{2} \mathrm{O}$ & 20 \\
\hline E 5 & 12.8 & 60 & Ammonium nitrate $\mathrm{NH}_{4}\left(\mathrm{NO}_{3}\right)$ & 30 \\
\hline E 6 & 11.2 & 45 & Potassium carbonate $\mathrm{K}_{2} \mathrm{CO}_{3} \cdot 2 \mathrm{H}_{2} \mathrm{O}$ & 10 \\
\hline E 7 & 15.1 & 75 & Sodium chloride $\mathrm{NaCl}$ & 20 \\
\hline
\end{tabular}


In each desiccator were placed two samples of wheat grain III and IV class weighing about $500 \mathrm{~g}$ each. The grain layer in the desiccators was 70-80 mm. Logger 100 TV temperature and relative humidity recorders were placed inside the grain samples with a recording interval of readings after 2 hours.

Periodically sampled grain from each desiccator for the determination of HP and humidity. Acid number of fat (ANF) was determined according to GOST 31700-2012, humidity was determined according to GOST 13586.5-2015. The error of the method for determining ANF is $10 \%$, humidity of $0.5 \%$.

\section{Results and discussion}

On Figure 1 shows how the relative humidity of the air in the desiccators changed during the storage of grain samples. In the desiccators E1, E3, E5 and E7, the maximum values of the relative humidity of $55 \%, 65 \%, 60 \%$ and $75 \%$, respectively, occurred after approximately two months of storage. In the desiccators $\mathrm{E} 2, \mathrm{E} 4$, and E6, the limiting values of the relative humidity of $35 \%, 44 \%$ and $45 \%$, respectively, occurred after approximately one month of storage.

Some fluctuations in relative humidity values are associated with temperature changes at the storage location (laboratory room), as well as with the opening of a desiccator when taking grain samples to determine humidity and ANF. Fluctuations in relative humidity did not exceed $3 \%$. In all grain samples (desiccators), the values of relative air humidity (Figure 1) and temperature (Figure 2) can be considered constant within the measurement error.

The graphs presented in Figure 2 characterize temperature fluctuations in the thermostat (E5), indoors (E1, E2, E3, E4 and E7) and in the refrigerator (E6). The temperatures inside the desiccators in a thermostat of $30{ }^{\circ} \mathrm{C}$ (E5) and in a refrigerator of $8 \div 10^{\circ} \mathrm{C}$ (E6) were set simultaneously on the 7 th -10 th day of storage. In the thermostat, the temperature practically did not change during storage; the oscillations were no more than $2{ }^{\circ} \mathrm{C}$. The maximum temperature fluctuations occurred in the laboratory, especially in the summer months (from $20^{\circ} \mathrm{C}$ to $27^{\circ} \mathrm{C}$ ). Temperature fluctuations in the refrigerator did not exceed $5^{\circ} \mathrm{C}$. From the data presented above, it follows that the maximum deviation of temperature values from the average value does not exceed $\pm 3.5^{\circ} \mathrm{C}$. Such a temperature change in the accepted experimental conditions does not significantly affect the result of determining the moisture content of the grain and the acid number of fat.

The period of reaching the equilibrium state of the grain in humidity (Figure 3) does not depend on the values of the rela-

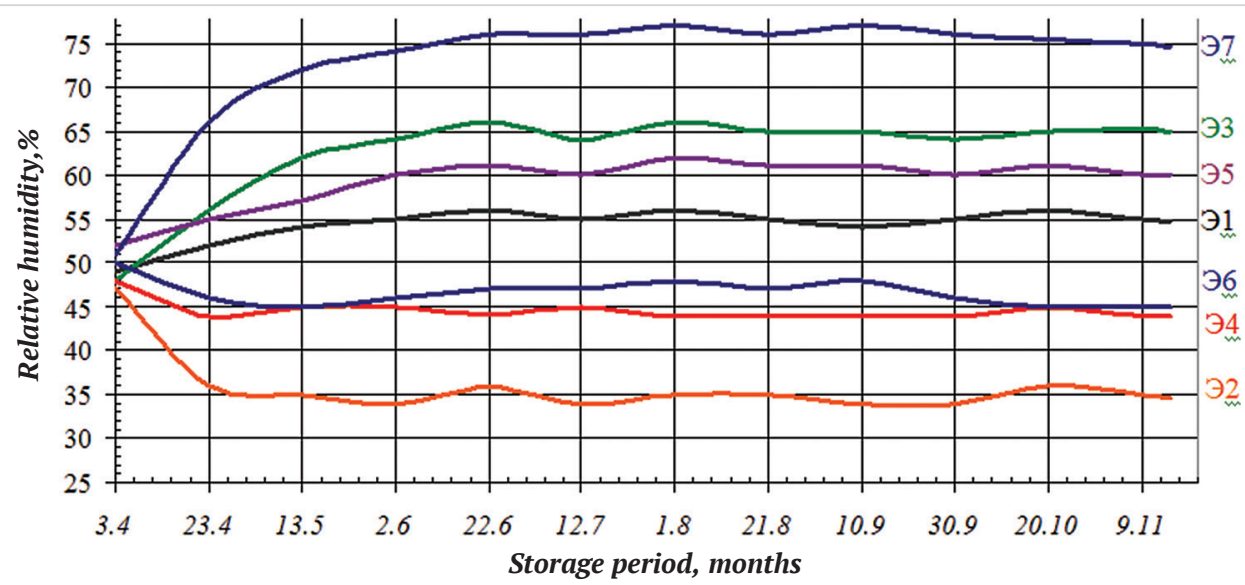

Figure 1. Change of relative air humidity in desiccators with grain samples.

(E1 ... E7 numbers of execrators according to Table 1)

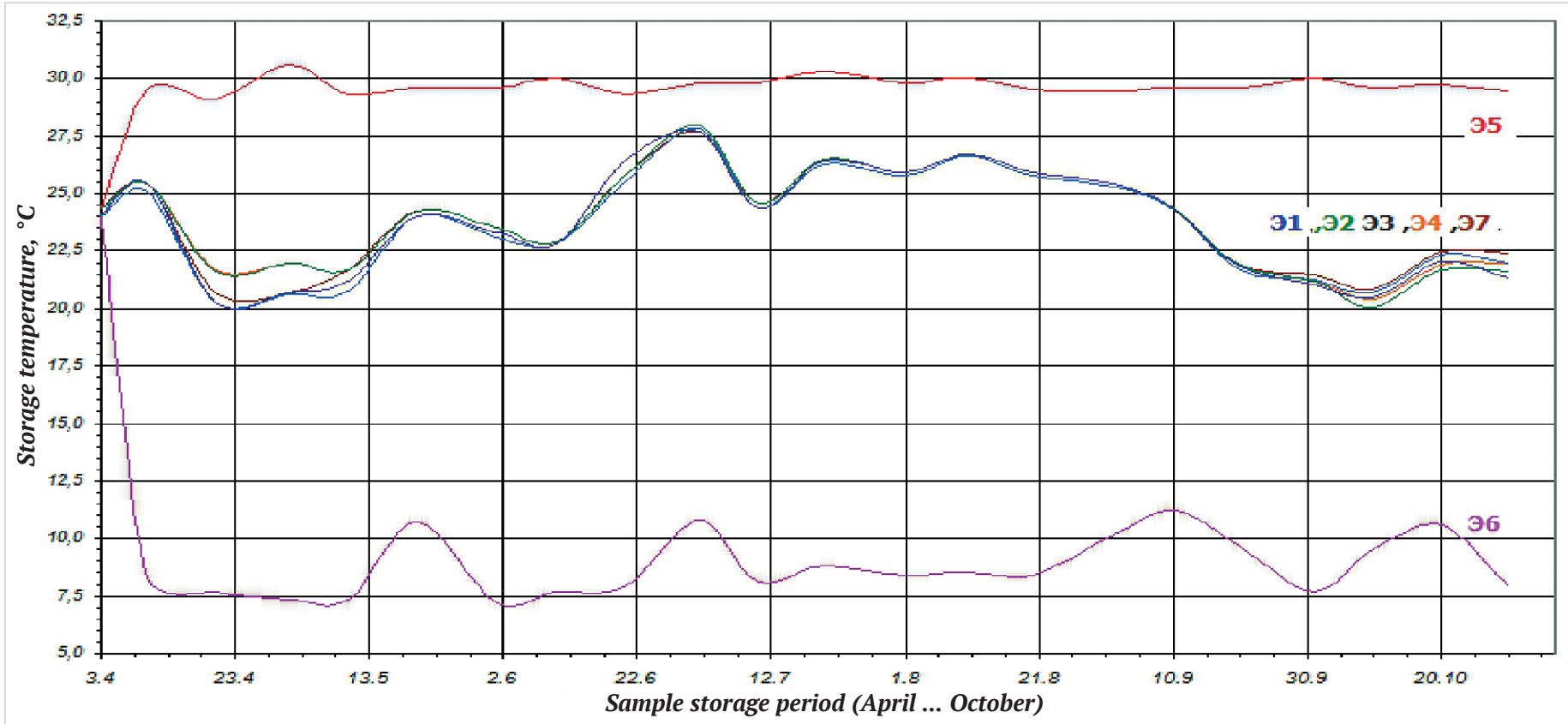

Figure 2. Temperature change in the desiccators during period of storage (E1 ... E7 numbers of the desiccators in accordance to Table 1) 


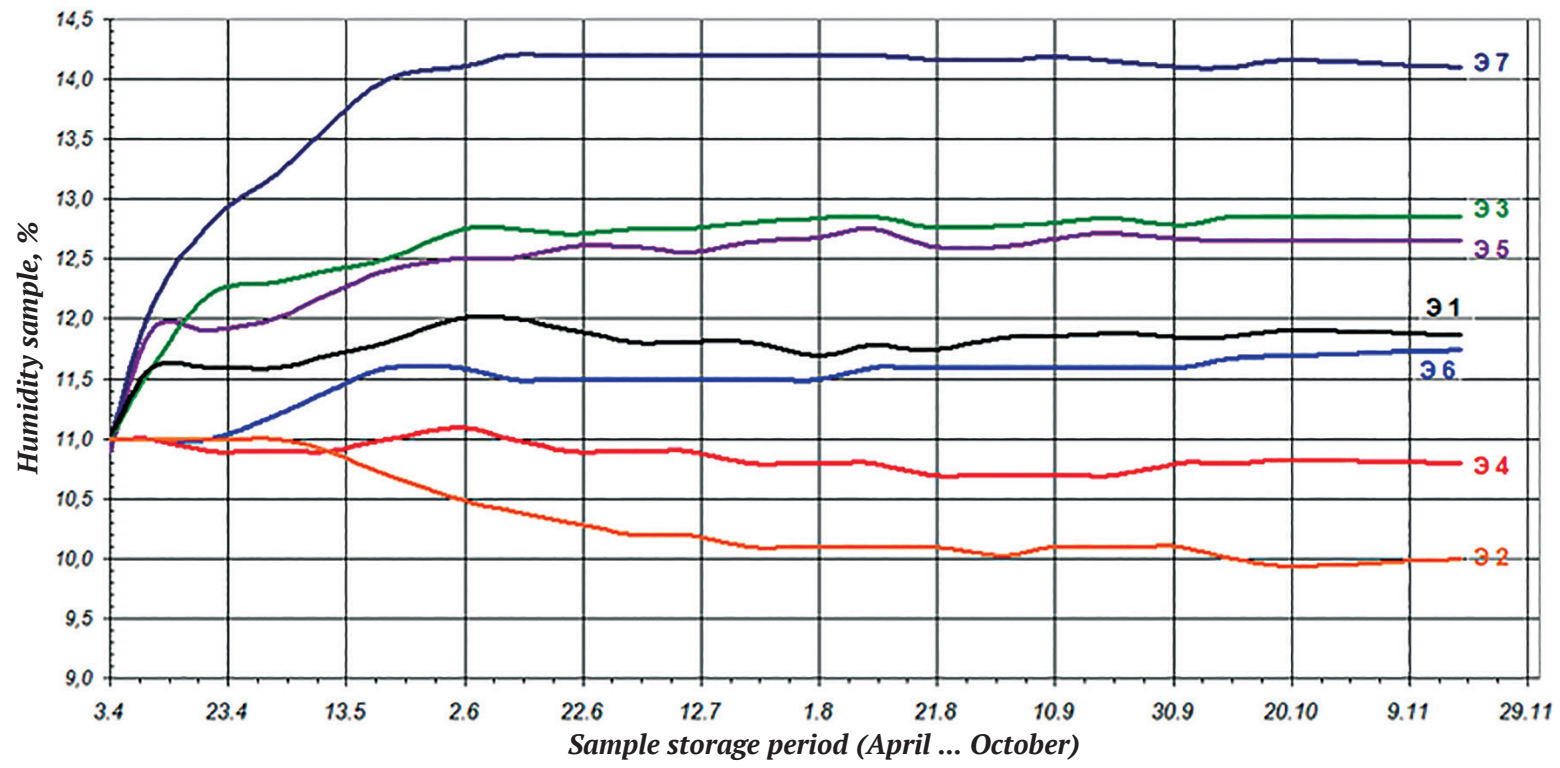

Figure 3. Change in moisture content of grain samples in desiccators during period of storage.

(E1 ... E7 numbers of desiccators according to Table 1)

tive humidity of the air. The values of equilibrium moisture for grains of the third and fourth classes practically did not differ between themselves. The state of equilibrium occurs independently of the class of wheat.

From the graphs presented in Figure 4, it follows that the change in the ANF of the wheat grain occurred in different ways:

$\square$ in a desiccator E6 for the entire period of storage of the value of this index remained at the initial level of $11.5 \mathrm{mg} \mathrm{KOH}$ per $1 \mathrm{~g}$ of fat, with $11 \%$ of grain moisture and relative humidity of $55 \%$;

$\square$ in desiccators E1, E2, E4, with grain moisture during storage $11.8 \% ; 10.0 \% ; 10.8 \%$ and relative humidity of $35 \%, 44 \%$, $50 \%$ to 6 months of storage of ANF also remained at the initial level of $11.5 \mathrm{mg} \mathrm{KOH}$ per $1 \mathrm{~g}$ of fat, and by the end of storage (November) there was an increase of ANF per $1 \mathrm{mg}$ of $\mathrm{KOH}$ per $1 \mathrm{~g}$ of fat, up to 12.5 (E1), and $12.3 \mathrm{mg} \mathrm{KOH}$ per $1 \mathrm{~g}$ of fat (E2 and E4);

$\square$ in the E3, E5, E7 desiccators, the grain moisture in the first 3 months of storage increased from $11.5 \%$ to $12.8 \%, 12.6 \%$ and $14.3 \%$, respectively, and remained at the same level for the entire storage period at a relative humidity of $65 \%$ (E3), $60 \%$ (E5) and $75 \%$ (E7). CNG of grains stored in these desiccators for the entire period increased from 11.5 to $14.0 \mathrm{mg}$ $\mathrm{KOH}$ per $\mathrm{g}$ fat. By the end of storage there was a sharp increase in QLH in E7 desiccators up to $17.0 \mathrm{mg} \mathrm{KOH}$ per $1 \mathrm{~g}$ of fat (relative humidity $75 \%$ and grain moisture $14.3 \%$ ) and E5 up to $15 \mathrm{mg} \mathrm{KOH}$ per $1 \mathrm{~g}$ fat and $60 \%$ relative humidity grain moisture $12.7 \%$.

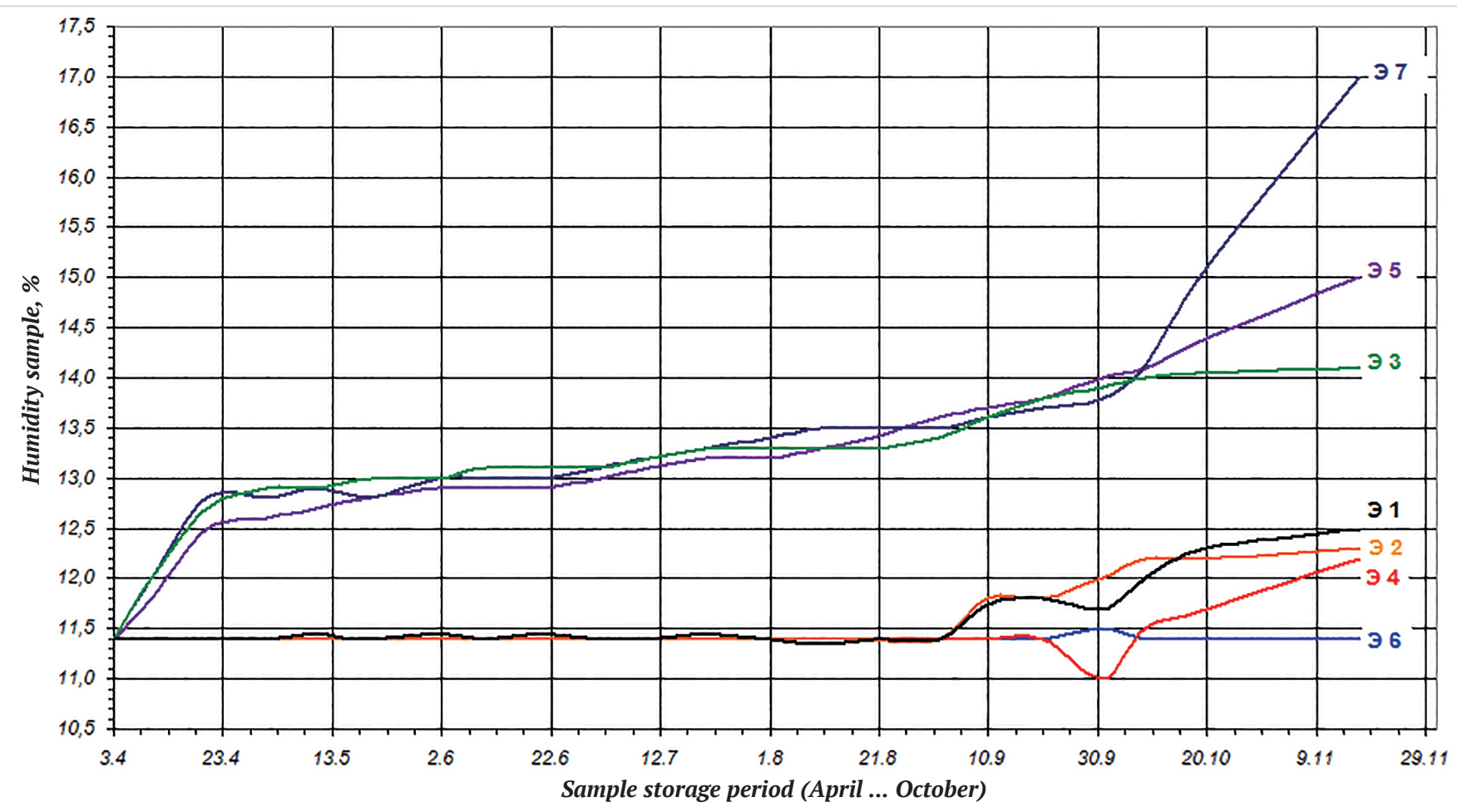

Figure 4. Changes in ANF in wheat samples of the 2017 harvest at different temperature and humidity storage conditions from April to November 2018 


\section{Conclusion}

Studies conducted in the laboratory during storage of food grains of wheat in desiccators at different values of relative humidity showed that in conditions of positive storage temperatures (up to $23{ }^{\circ} \mathrm{C}$ ), relative humidity up to $70 \%$, providing grain moisture from $10 \%$ to $14 \%$ ANF did not exceed $15 \mathrm{mg} \mathrm{KOH}$ per $\mathrm{g}$ fat.

An increase in relative air humidity up to 75 and an increase in grain moisture above $14 \%$ leads to a sharp increase in the acid number of fat due to the development of microflora (E7), in the period September-November.

Less intensively, in comparison with E7, ANF increased during the specified period in the $\mathrm{E} 5$ desiccator, in which the relative humidity of the air was $60 \%$ and the temperature was $30{ }^{\circ} \mathrm{C}$ (stored in a thermostat). With an even lower growth rate, there was an increase in ANF in the desiccator E3, in which the relative humidity of air was $65 \%$ and the average temperature was $23^{\circ} \mathrm{C}$.

From the data presented above it follows that the relative humidity of air over $60 \%$ affects the increase in ANF values. The greater the relative humidity of the air, the more intense the ANF increases.

When storing a grain sample, in a desiccator E5, the relative humidity of the air was lower than in a desiccator E3, but higher temperatures and more intense ANF grows. These data confirm the effect of storage temperature on ANF. With increasing temperature, the value of CNG increases.
For wheat grains of the third and fourth classes, there were no characteristic differences in the change of ANF. Class wheat does not affect the variability of ANF.

Our studies have shown that the results of laboratory experiments are comparable to production data during the storage of flour, this allows us to take into account the results obtained in the production storage of wheat.

Based on the above, we can draw the following conclusions.

Acid number of fat is a sensitive indicator of the stability of the grain mass (applied to wheat grain), which characterizes the suitability of the grain for further use in subsequent processing into flour.

It must be stated that such factors of grain storage as temperature and humidity are functionally related to the abovementioned indicator.

The storage conditions of wheat at temperatures in the range from $20^{\circ} \mathrm{C}$ to $30{ }^{\circ} \mathrm{C}$ significantly affect the value of ANF, however, a significant increase in ANF occurs not earlier than 6 months of storage, according to the conditions of the experiment, but in fact from the moment of harvesting - AugustSeptember 2017

The value of the relative humidity of the air affects the change in ANF at storage temperatures above $20-25{ }^{\circ} \mathrm{C}$ more significantly than at temperatures below $20^{\circ} \mathrm{C}$. This effect becomes significant after 6 months of storage.

\section{REFERENCES}

1. Kozmina, N.P. (2000). Biochemistry of grain and products of its processing. - M, Kolos,- 250 p. (in Russian)

2. Priyezzheva, L.G., Meleshkina, E.P., Sorochinsky, V.F., Yaickikh, A.V., Verezhnikova, I.A. (2017). The safe storage of bakery wheat flour at different storage conditions. Bread products, 6, 46-49. (in Russian)

3. Priyezzheva, L.G., Meleshkina, E.P. (2014). The Use of Indicators of Acid Number Fat to Set Standards for Safe Storage and Validity Grain Products. International scientific and practical conference «Innovative production technologies and storages of material values for the state needs». M, Scientific Research Institute of Problems of Storage of Rosrezerv - 194-202. (in Russian)

4. Manzhesov, V.I., Popov, I.A., Maksimov, I.V., Kalashnikova, S.V., Churikova, S.Yu., Schedrin, D.S. (2017). Technology of postharvest processing, storage and prerealizable preparation of products of crop production. Saint Petersburg, Lan. - 624 p. ISBN: 978-5-8114-2478-8 (in Russian)

5. Voblikov, E.M. (2001). Postharvest processing and storage of grain. Rostovna-Don MarT, -229 p. (in Russian)

6. Drincha, V.M. Tsydendorzhiyev, B.Zh. (2010). Reserves of decrease in losses of grain at storage, Feeds, 7, 59-60. (in Russian)

7. Priyezzheva, L.G., Sorochinsky V.F., Meleshkina E.P. (2015). Acid number of fat - an indicator of safe storage and realization of grain products. International scientific and practical conference «Food. Ecology. Quality - 2015». -
M.: MGUPP. 88-97. (in Russian)

8. Priyezzheva, L.G., Meleshkina. E.P. (2018). The specified norms of safe storage and the validity of wheat bread flour of the premium on acid number of fat. Bread products, 6, 44-47. (in Russian)

9. Voyskovoy, A.I., Zubov, A.E. (2008). Storage and assessment of quality of grain and seeds: manual, Stavropol, Agrus. - 146 p. ISBN 5-9596-0164-8 (in Russian)

10. Priyezzheva, L.G., Meleshkina, E.P., Sorochinsky, V.F., Verezhnikova, I.A., Ignatova, L.G., Koval, A.I. (2017). Long-term storage of wheat flour in laboratory and production conditions. Bread products, 10, 44-47. (in Russian)

11. Tumanovskaya, N.B. (2012). Technology of storage of grain: Educational and practical grant, M, MSU. - 192 p. (in Russian)

12. Yukish, A.E., Ilyina, O.A. (2009). Tekhnika and technology of storage of grain. M, DeLi print. - 717 p. ISBN 978-5-94343-180-7 (in Russian)

13. GOST 29244-91 (ISO483-88)«Plastics. Small enclosures for conditioning and testing using aqueous solutions to maintain relative humidity at constant value «Moscow: Standardinform. - 2004. - 11 p. (in Russian)

14. Constant relative humidity over saturated solutions of salts. [Electronic resource: http://tehtab.ru/Guide/GuidePhysics/Humidity/SaturatedSaltSolutionsHumidity Access date 20.04.2019] (in Russian)

\section{AUTHOR INFORMATION}

Yury D. Gavrichenkov - candidate of technical sciences, docent, senior researcher, laboratory of «Elevator-Storage Facilities and Grain Storage», All-Russian Scientific and Research Institute for Grain and Products of its Processing - Branch of V.M. Gorbatov Federal Research Center for Food Systems of RAS, 127434, Moscow, Timiryazevskoe shosse, 11. Tel.: +7-499-976-34-21, e-mail: vniizdocum@rambler.ru

*corresponding author

Alexander S. Razvorotnev - candidate of technical sciences, head of the laboratory, «Elevator-Storage Facilities and Grain Storage», All-Russian Scientific and Research Institute for Grain and Products of its Processing - Branch of V.M. Gorbatov Federal Research Center for Food Systems of RAS, 127434, Moscow, Timiryazevskoe shosse, 11. Tel.:+7-499-976-34-21, e-mail: vniizdocum@rambler.ru

Ivan A. Kechkin - junior researcher, laboratory «Elevator-Storage Facilities and Grain Storage», All-Russian Scientific and Research Institute for Grain and Products of its Processing - Branch of V.M. Gorbatov Federal Research Center for Food Systems of RAS, 127434 , Moscow, Timiryazevskoe shosse, 11. Tel.: +7-499-976-34-21, e-mail: vniizdocum@rambler.ru

Irina A. Verezhnikova - lead engineer, laboratory «Biochemistry and a microbiology of grain and grain products», All-Russian Scientific and Research Institute for Grain and Products of its Processing - Branch of V.M. Gorbatov Federal Research Center for Food Systems of RAS, 127434, Moscow, Timiryazevskoye shosse, 11. Tel.: +7-499-976-34-21, e-mail: vniizdocum@rambler.ru

Authors are equally relevant to the writing of the manuscript, and equally responsible for plagiarism

The authors declare no conflict of interest

Received 16.05.2019 Accepted in revised 06.06.2019 Accepted for publication 16.06.2019 